\title{
New Trend to Measure the Saturation Point and Suction in Granular Soil
}

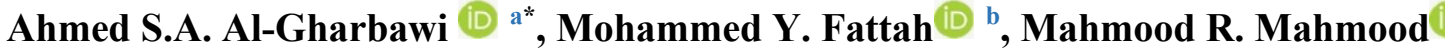 \\ ${ }^{a}$ Ph.D. student, Civil Engineering Department, University of Technology, Baghdad. \\ ahmedsgharbawi@yahoo.com \& 40331@,uotechnology.edu.iq. \\ ${ }^{\mathrm{b}}$ Professor, Civil Engineering Department, University of Technology, Baghdad \\ 40011@uotechnology.edu.iq. \\ ${ }^{\mathrm{c}}$ Assistant Professor, Civil Engineering Department, University of Technology, Baghdad. \\ 40079@uotechnology.edu.iq. \\ *Corresponding author.
}

Submitted: 01/10/2019

Accepted: 04/02/2020

Published: 25/11/2020

\section{K E Y W O R D S}

Granular soil, matric suction, soil water characteristic curve, tensoimeter, soil moisture content sensor.

\begin{abstract}
A B S T R A C T
There are many methods to measure the suction and saturation point of any soil and the most used is Tensiometer. The objective of this research is to investigate a new trend to measure the saturation point and suction by using soil moisture content sensors (SMCS) and compare the procedure with tensiometer for the granular soil. The soil in this study has been prepared at three relative densities $(5 \%, 35 \%$ and $75 \%)$ used. The results show that the readings of SMCS become stable when the water content is more than 20\% with different relative densities. The relative density did not affect the SMCS reading when approximately reaching the saturation point.
\end{abstract}

How to cite this article. A. S.A. Al-Gharbawi, M. Y. Fattah, and M.R. Mahmood, "New Trend to Measure the Saturation Point and Suction in Granular Soil," Engineering and Technology Journal, Vol. 38, Part A, No. 11, pp. 1570-1579, 2020.

DOI: https://doi.org/10.30684/etj.v38i11A.746

This is an open access article under the CC BY 4.0 license http://creativecommons.org/licenses/by/4.0

\section{INTRODUCTION}

The modeling attitude of an unsaturated soil requires measurement of suction in the soil and their difference with water content, which it is known as the soil-water-characteristic-curve (SWCC). The soil suction and moisture content relationship have commonly considered one of the most important characteristics [1].

The soil-water-characteristic-curve(SWCC) was developed as an important parameter in water management in agricultural, hydrology and the research in soil sciences, the SWCC was used widely to estimate the properties of unsaturated soil, [2-4].

The definition of the total suction is the soil-water free energy, and it is calculated as a ratio of partial stress of the evaporation of water in equilibrium with the water in the soil, relative of partial 
stress of the evaporation of water in equilibrium with a solution identical in composition with a pool of soil-water. The matric suction in unsaturated soil is calculated directly by measuring the reflecting of the pore water pressure, [5].

The suction technique measurement are needed more studying and improving because of the most methods of measuring the suction have a weakness including such aspects as reliability, practicality, the range of application, and cost, [5].

Tensiometers and axis translation techniques rely on the unique properties of high_air_entry(HAE) materials. High_air_entry is the materials that considers as a microscopic pores relatively uniform size and size distribution. When the high_air_entry material is saturated with water, the surface tension maintained at the gas-liquid interfaces formed in the material's pores allows a pressure difference to be sustained between gas and liquid phases located on either side. Physically, surface tension acts as a membrane for separating the two phases, thus allowing negative water pressure to be directly measured, as in a tensiometer, or the difference between water pressure and air pressure to be directly controlled as axis translation, [6].

There are several studies depends on different methodologies to develop the measuring of the suction. The methodologies for the measuring the suction in the soil depends on a various factors such as (viz., type of the soil, measurement methodology, range of the suction measurement, equilibration time, and presence of salts or contaminants in the soil) that may effect on the results and the SWCC. Sreedeep and Singh [7] studied the SWCC by using several methodologies and it has been effected in the range of the soil suction determination. As such, it is essential to highlight the range of suction values involved for establishing the SWCC, to facilitate unambiguous modeling and to precisely understand the behavior of unsaturated soil.

Fattah et al. [7] used the filter papers for investigating the total and matric suctions. Three soils from different sites from Baghdad were used in there study and then Nacl salt was used to mix with soil. They concluded that with increase of filter paper moisture content there is a linear decrease in both total and matric suctions. When adding the Nacl salt to the soil there are good increases in total and matric suctions.

Also Fattah et al. [8] used small scale and large scale modeling by using bentonite and bentonite stabilized by sand of a different percents 30,40 and $50 \%$ to investigate the changes in the suction of the soil on volume change, swelling pressure, and permeability as well as expansion index. It was concluded that when adding 50\% sand to bentonite there are decreasing in swelling potential of the soil.

The main objective of this research is to investigate a new trend to measure suction and determine the saturation point by using soil moisture content sensor (SMCS).

\section{Materials}

\section{Soil}

In this research, granular gypseous soil brought from Tikrit city with gypsum content $49 \%$ was used. The physical properties are illustrated in Table 1 and the distribution of the grain size is illustrated in Figure (1). According to the unified soil classification system(USCS), the soil is classified as (SP).

Table I: Soil properties. 


\begin{tabular}{cc}
\hline Gypsum content $(\chi) ;(\%)$ & 49 \\
Specific Gravity; Gs & 2.41 \\
Liquid limit; (\%) & 26 \\
Plastic Limit; (\%) & N.P \\
Gravel; (\%) & 0 \\
Sand; (\%) & 96 \\
Fines; (\%) & 4 \\
$\mathrm{D}_{60} ;(\mathrm{mm})$ & 0.4 \\
$\mathrm{D}_{30} ;(\mathrm{mm})$ & 0.2 \\
$\mathrm{D}_{10} ;(\mathrm{mm})$ & 0.11 \\
Uniformity coeff.; Cu & 3.64 \\
Curvature coeff.; Cc & 0.91 \\
O.M.C; $(\%)$ & 12 \\
$\gamma_{d \text { min. }} ;\left(\mathrm{kN} / \mathrm{m}^{3}\right)$ & 12.12 \\
$\gamma_{d \text { max. }}$ (kN/m & 17.45 \\
Classification & $\mathrm{SP}$ \\
\hline
\end{tabular}

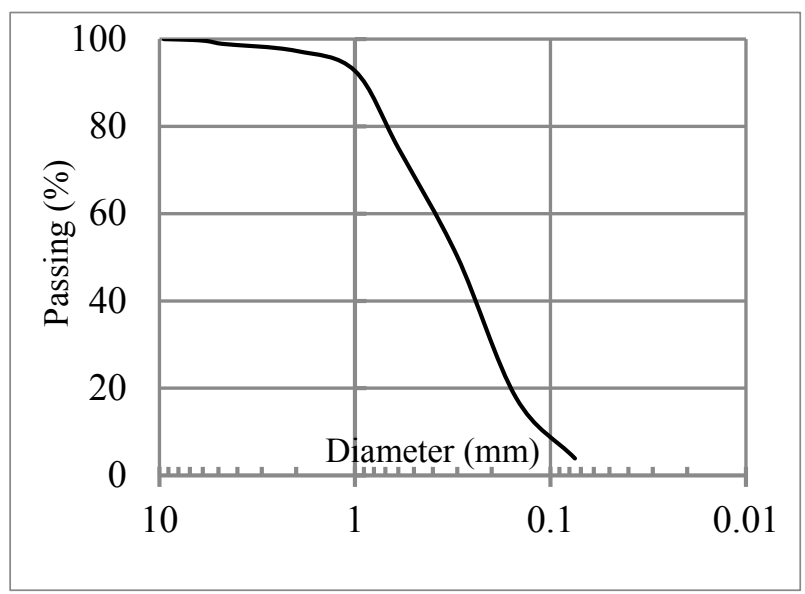

Figure 1: Grain size distribution.

\section{II. . Tensiometer}

The description of measurement principles, construction guidelines and operating was provided by Stannard in 1992 as cited by [5]. The standard tensiometer is a tube filled with water with the high_air_entry and contains a ceramic at the end of the tube, the ceramic is using as a sensor to determine the negative pore water pressure. The ceramic is basically a small probe using to build a saturated hydraulic connection between the pore water pressure and the ceramic sensor. There are two types of the pressure sensor mechanical Bourdon type gauge and electronic diaphragm type transducer. The tensiometer diagram of the type that used in the laboratory and in this research is illustrated in Figure (2).

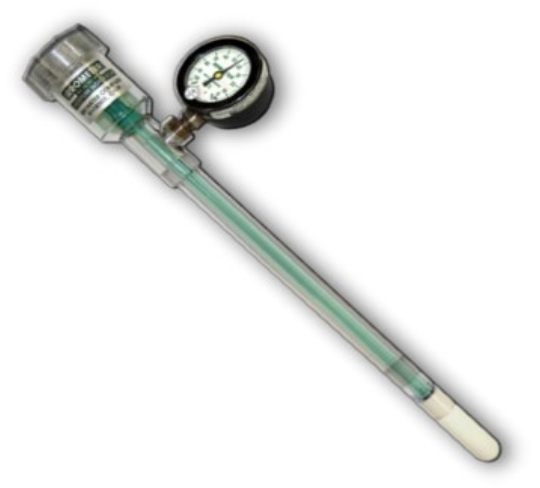




\section{Figure 2: Tensiometer.}

\section{Soil moisture content sensor SMCS}

The type of this sensor is used to show the soil moisture content by the dielectric properties of the water in the soil. It has been contained two electrodes and it has been inserted in the soil to measure the moisture content, the sensor is sent an electromagnetic signal to the soil and record the water content between the soil particles, as illustrated in Figure (3). The accurate reading of the sensor depends on the good contact between the soil and the sensor, [9].

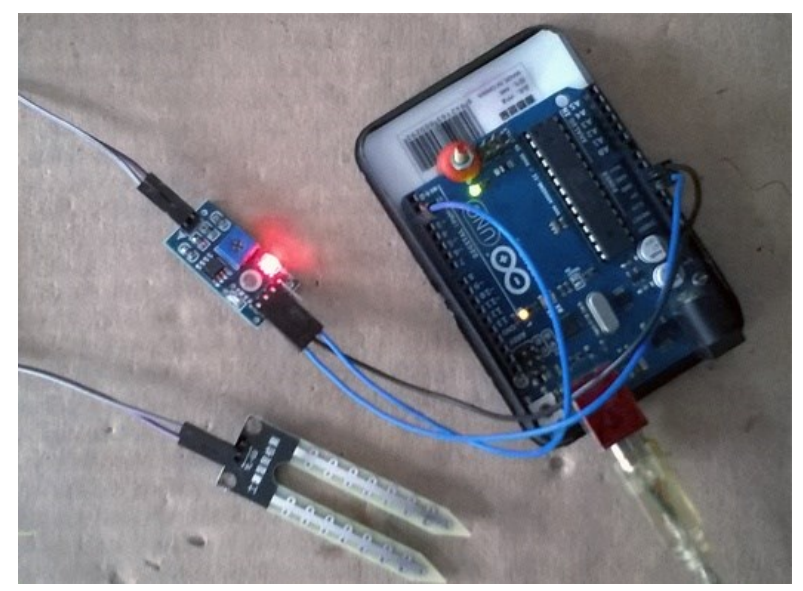

Figure 3: SMCS with arduino.

\section{MODEL PREPARATION AND TESTING}

This research depends on 18 tests carried out in CBR mould filled with soil at different water contents and with three relative densities $(5 \%, 35 \%$ and $75 \%)$. After preparation, the mould was covered carefully to prevent water leakage from the mould and the sample was left for 24 hours.

The test depends on inserting the tensiometer in the CBR mould and two SMCS ware inserted; one of them is aligned vertically and the other is horizontally as illustrated in Figure (4). 


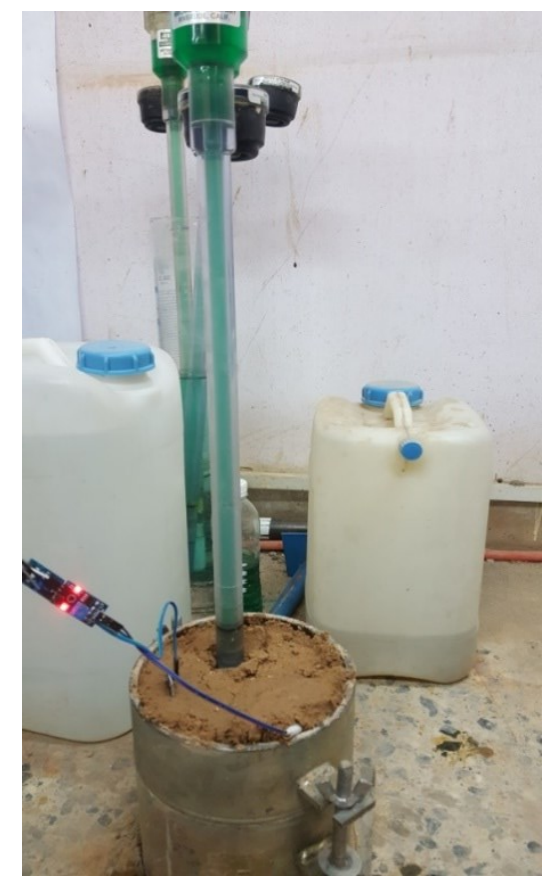

Figure 4: Testing apparatus.

\section{Presentation And discussion test Results}

Figure (5) illustrates the water content and tensiometer reading for sample prepared at R.D $=5 \%$. Figure (6) illustrates the water content and SMCS readings for sample prepared at R.D $=5 \%$.

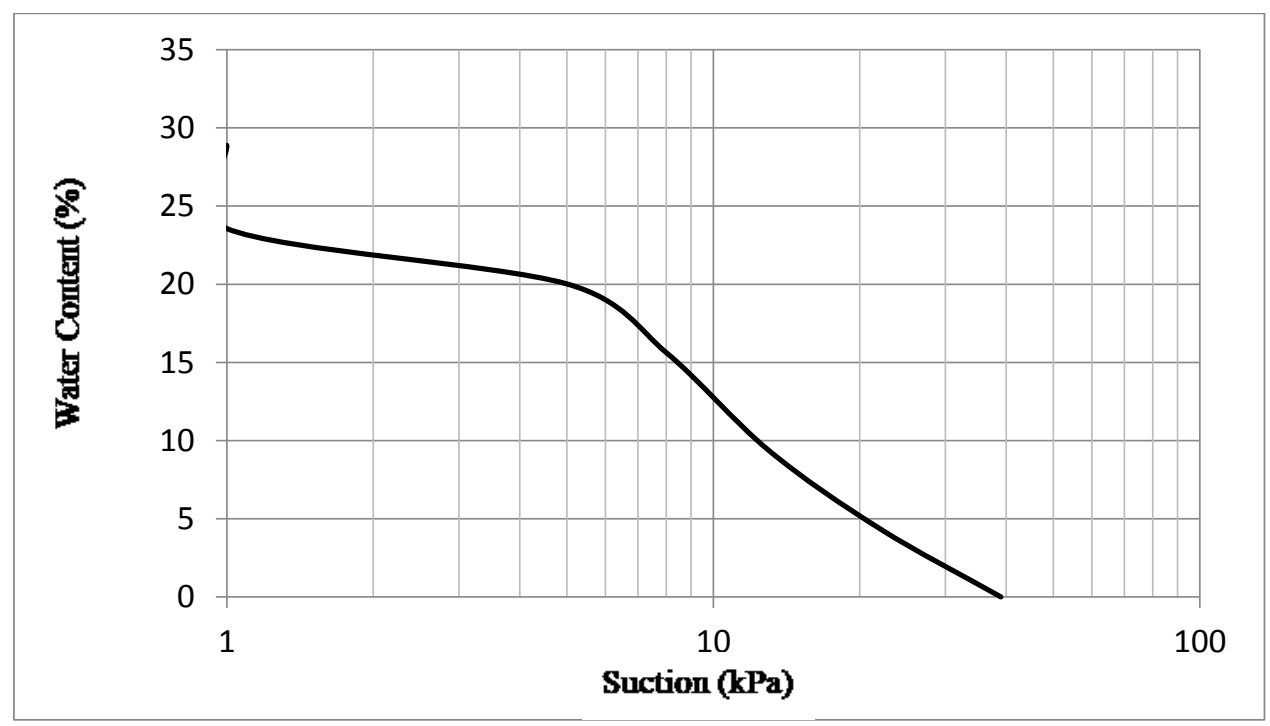

Figure 5: Tensiometer readings for sample prepared at R.D $=\mathbf{5} \%$. 


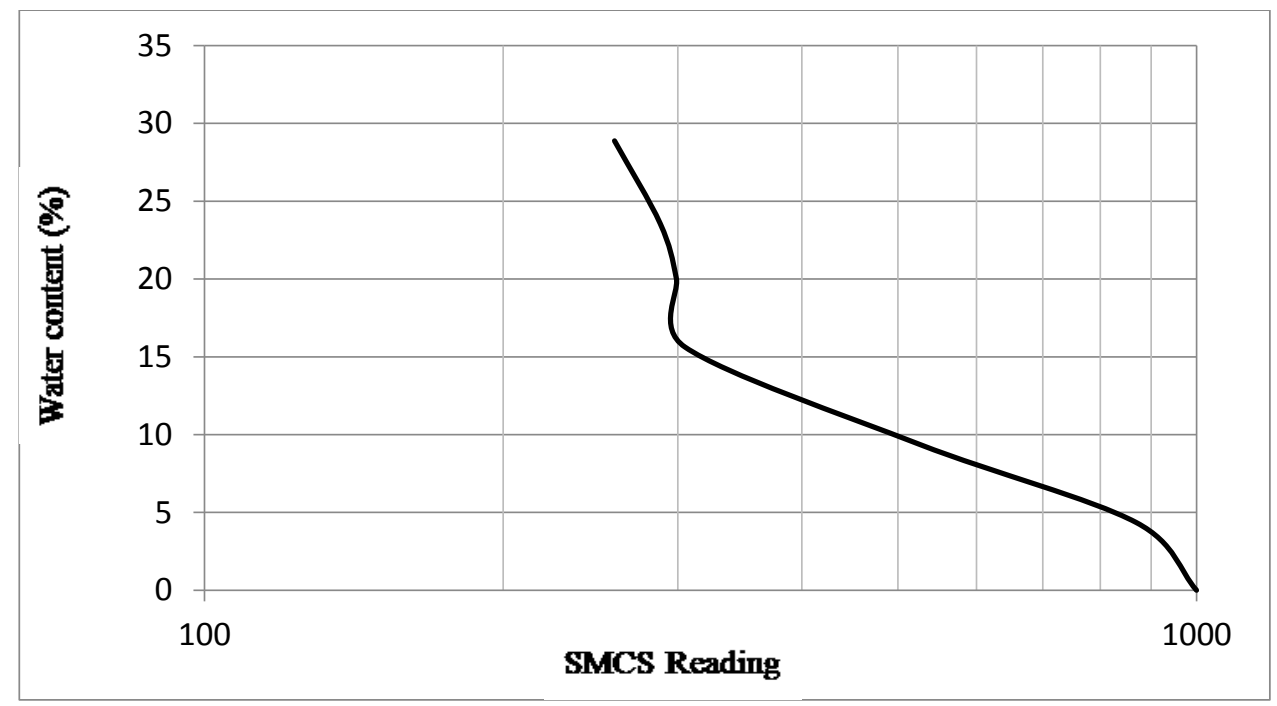

Figure 6: SMCS readings for sample prepared at R.D $=\mathbf{5 \%}$.

Figure (7) illustrates the water content and tensiometer reading for sample prepared at R.D 35\%. While Figure (8) illustrates the water content and SMCS readings for sample prepared at the same relative density.

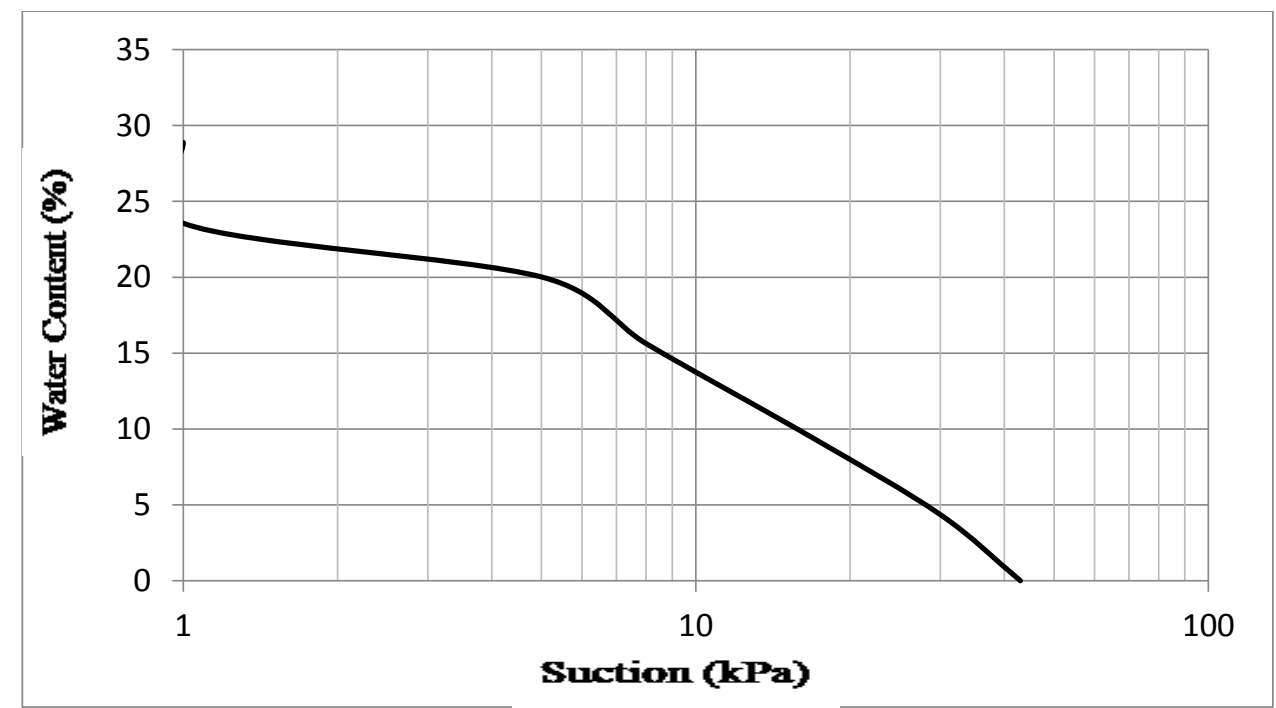

Figure 7: Tensiometer readings for sample prepared at R.D 35\%

The trend of water content for three soil samples showed a sharp decrease in the beginning and then decreased slowly with the amplifying of soil water suction. In low suction range $(<10 \mathrm{kPa})$, soil water in large pores was mainly drained, as the large pores contained lots of water. Based on this, the soil water content decreased sharply. The differences of SWCCs of the granular soil are noticeable with the increasing of the soil relative density. 


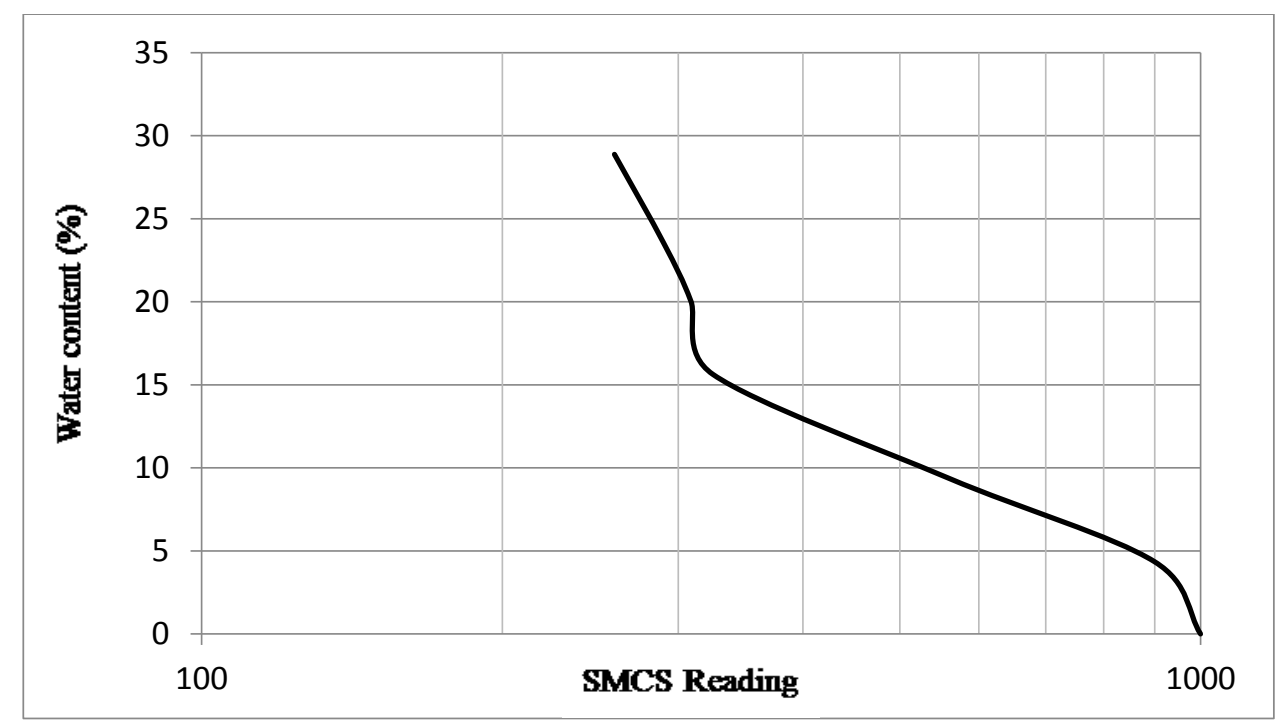

Figure 8: SMCS readings for sample prepared at R.D 35\%

Figure (9) illustrates the water content and tensiometer readings for sample prepared at R.D 75\%, while Figure (10) illustrates the water content and SMCS readings for sample prepared at the same relative density.

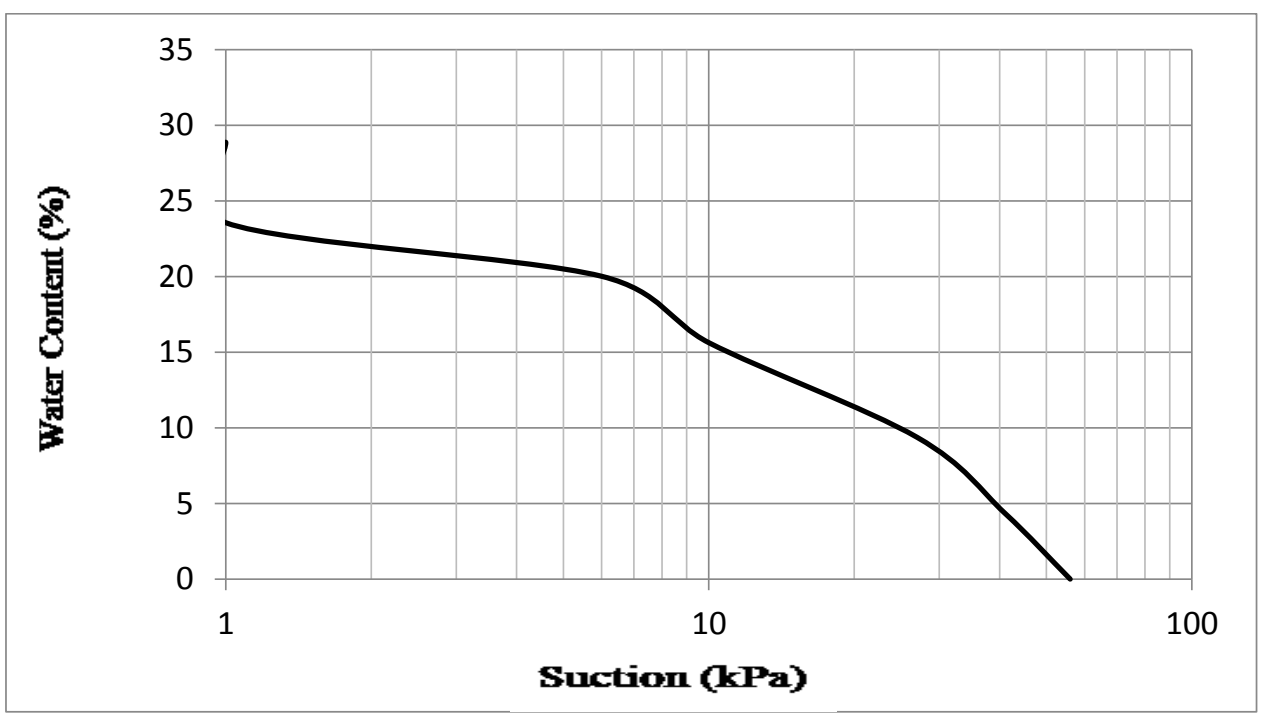

Figure 9: Tensiometer readings for sample prepared at R.D 75\% 


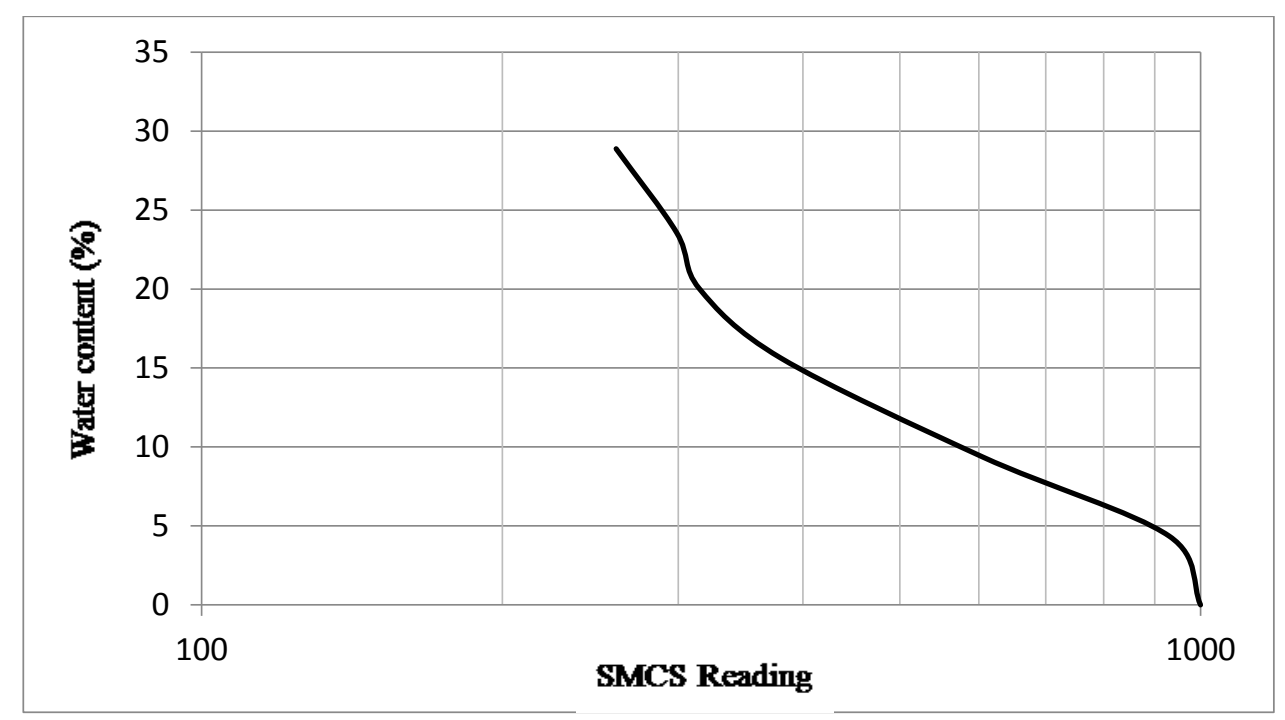

Figure 10: SMCS readings for sample prepared at R.D $75 \%$

The summary of test results is illustrated in Figures (11) and (12). Figure (13) illustrates the SMCS reading with the matric suction at the same water content, the SMCS can be read directly for the corresponding to tensiometer at the same water content.

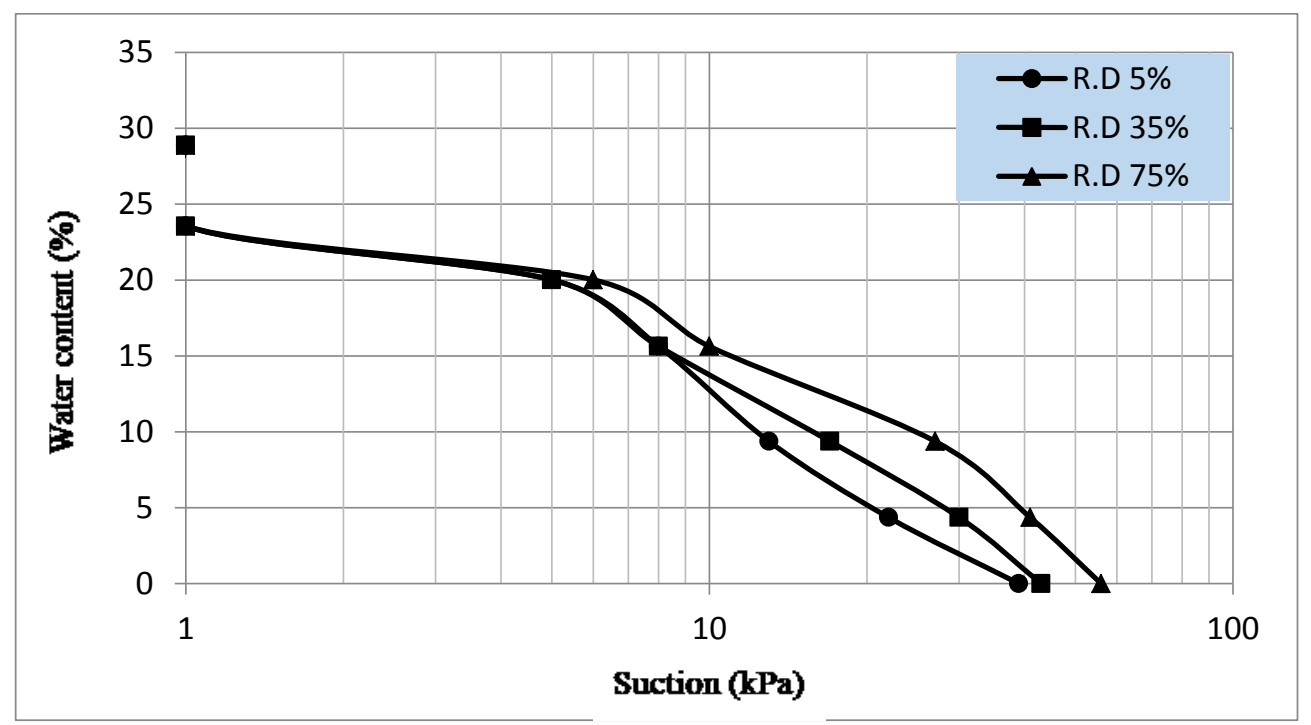

Figure 11: Relationship between tensiometer readings and water content for soil with different relative densities. 


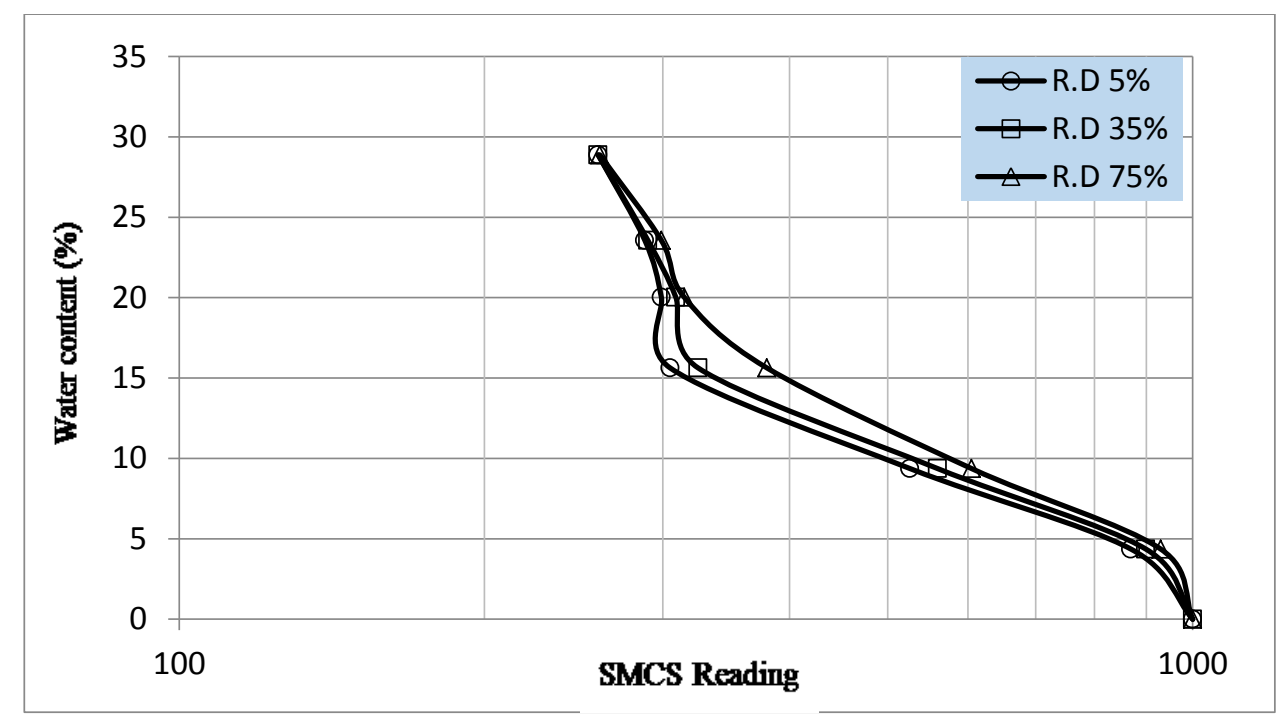

Figure 12: Relationship between SMCS readings and water content for soil with different relative densities.

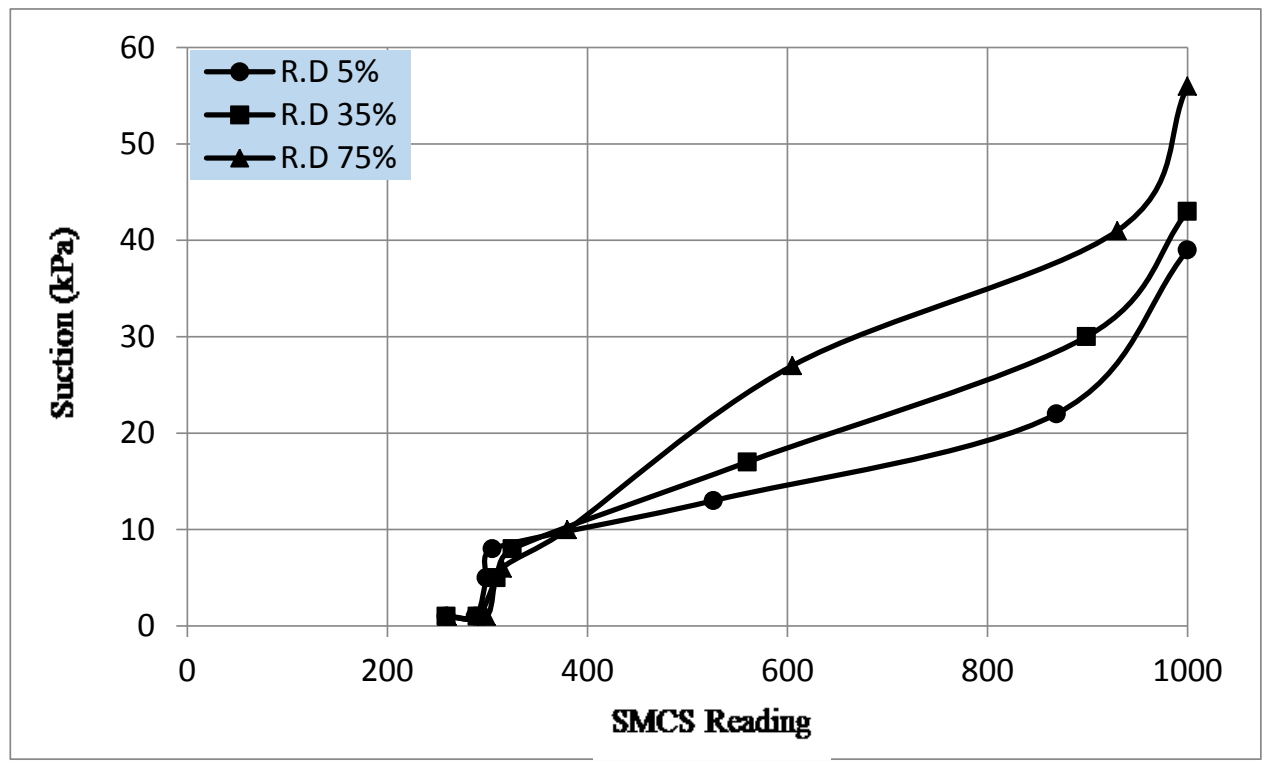

Figure 13: Relationship between SMCS readings with the matric suction at the same water content with different relative densities.

\section{Conclusions}

From this study, the following conclusions can be summarized:

1. The using of SMCS is a good alternative to tensiometer especially to show the saturation point.

2. The relative density did not affect the SMCS reading when approximately reaching the saturation point.

3. The readings of SMCS become stable when the water content is more than $20 \%$. 


\section{References}

[1] W.R. Gardner (1968). Availability and measurement of soil water. Water Deficits and Plant 524 Growth, 1: $107-135$.

[2] M. Y. Fattah, A. Al-Obaidi, and M. K. Al-Dorri, (2018), Determinationof the Water Characteristic Curve for Unsaturated Gypseous Soil from Model Tests, Journal of Applied Sciences, Vol. 9, pp. 544-551.

[3] M. Y. Fattah, A. Al-Obaidi, and M. K. Al-Dorri, (2018), Variation of Suction during Wetting of Unsaturated Collapsible Gypseous Soils, International Journal of Engineering \& Technology Sciences, Vol. 7, pp. 79-85.

[4] N. Ganjian, Y.P.Pisheh, S.M.M.M.Hosseini, (2007), Prediction of Soil-Water Characteristic Curve Based on Soil Index Properties, Experimental Unsaturated Soil Mechanics. Springer Proceedings in Physics, vol 112. Springer, Berlin, Heidelberg.

[5] H. Pan, Y. Qing, L. Pei-yong, (2010) Direct and Indirect Measurement of Soil Suction in the Laboratory, Electronic Journal of Geotechnical Engineering, Vol. 15, Bund A.

[6] N. Lu, and W.J. Likos, (2004). "Unsaturated Soil Mechanics," John Wiley \& Sons, Inc., Hoboken, New Jersey, USA.

[7] S. Sreedeep and D.N. Singh, (2011), Critical Review of the Methodologies Employedfor Soil Suction Measurement, International Journal of Geomechanics, ASCE, Vol. 11, pp. 99-104

[8] M. Y. Fattah, A.Y. Yahya, M.Th. Al-Hadidi, B.A. Ahmed, (2013), "Effect of Salt Content on Total and Matric Suction of Unsaturated Soils”, European Scientific Journal, Vol. 9, No. 9, pp. 228-245.

[9] M. Y. Fattah, N.M.Salim, E.J.Irshayyid, (2017), "Influence of Soil Suction on Swelling Pressure of Bentonite-sand Mixtures", European Journal of Environmental and Civil Engineering, https://doi.org/10.1080/19648189.2017.1320236, Taylor \& Francis.

[10] T. Maughan, L.N. Allen, and D. Drost, "Soil Moisture Measurement and Sensors for Irrigation Management," AG/Irrigation/2015-01pr, October, 2015. 